\title{
Applying E-learning Technologies to Library Information Literacy Instruction
}

\author{
Jamie Ward \\ Dundalk Institute of Technology Library, Ireland
}

\begin{abstract}
Academic libraries have adopted and adapted the e-learning technologies for delivery of their Information Literacy programmes. This chapter describes some of the ways in which academic librarians have been very inventive in using emerging technologies to enhance their instructional content. By using a case study of DkIT the chapter details how information literacy and the elearning technologies emerged together. E-learning platforms like the virtual learning environments (VLE) are the natural place for libraries to use as portals for their IL instruction. This chapter argues that using the VLE (with the inherent instructional interaction made possible by this technology), and adopting some amalgam of the newer teaching styles like problem-based learning and blended learning techniques completes the IL circle for librarians. Librarians now have the tools at their disposal to finally fulfil the promises we undertook when we embarked on our information literacy programmes.
\end{abstract}

\section{KEYWORDS}

inductive transfer; information literacy; learning transfer; Moodle; online learning tutorial; social bookmarking; virtual learning environment; webcast

\section{INTRODUCTION}

We live in interesting times for librarians. The amount of information and means of access to this information has dramatically increased in volume and complexity. Methods of accessing this information and how people engage with the different information media are also in constant flux. This preponderance of networked information that has become available to library users has necessitated the expansion of librarians' instructional role to help equip our users in the skills required to access information effectively. The librarian's remit has been broadened and this has compelled us to explore the possibilities of e-learning technologies to assist us in this extended remit. The demand for library instruction has also required librarians to really engage with the science of teaching and how we employ different methods of instruction. We as a profession now accept that the increasing volume of information is only of value to an academic community when it is employed in a meaningful way within the process of learning.

This chapter is an attempt to examine the convergence of the factors that led to the new outlook for information provision and will look at the possibilities for library instruction using the new elearning technologies. I will be detailing our own case study in Dundalk Institute of Technology in an attempt to draw all the elements together and endeavour to show that no single element can be taken in isolation from the other. By detailing our own evolutionary experience with 
information literacy and e-learning, I hope to demonstrate that an academic library has the instructional imperative and the skills to design the necessary e-learning instruments for user support and training. I will also show that whilst librarians working within the academic environment have tried to address and fulfil our duty to our community, we have found that a new collaborative model of engagement with academics will be the best template for designing future library instruction.

The case history is also an attempt to show how different technologies were employed for all our digitally facilitated instruction and engagement with library users and how this culminated in a 'blended learning' approach to helping students become information literate. Blended learning is using a variety of learning methods, teaching resources and techniques and applying them in an interactive way for students. The case history is also an attempt to highlight that libraries' sometimes uneven implementation of information literacy and their idiosyncratic adoption of different technologies, as vehicles for library instruction, have created a new fresh dynamic for academic libraries. This dynamic has had the effect of placing libraries as central, once again, within the learning processes for students in academic institutions. Finally, I will be examining some ideas on what more libraries can do to support the community we serve. The future trends section is based on our own experiences to date and is informed by an examination of some of the developments that may emerge from the current trends within teaching practice and how these can help shape librarians' use of available e-learning technologies. Utilising networked information to enhance knowledge is a complex human as well as technical process that requires some background explanation of what librarians are dealing with.

\section{BACKGROUND}

The term 'Information Literacy' (IL) is widely used by the library profession to describe what we believe is an essential attainment for students and staff to be effective scholars. For librarians the main aims of IL is to participate in developing students who can 'recognise what information is needed and have the ability to locate, evaluate and use effectively the information needed' (American Library Association, 1989). One of the main avenues being used to achieve the standards set by IL is e-learning. E-learning is defined as 'learning facilitated and supported through the use of information technologies' (Melling, 2006, p. XII ). To date libraries have been exemplars in adopting and adapting the e-learning technologies available in the furtherance of the goals of information literacy.

Yet there hasn't been, nor can there be, a consistent approach within the academic libraries of Ireland to the delivery of IL modules and therefore no correspondingly consistent approach to using the technologies available in the delivery of their IL training. Even with librarians having approximately the same definition of IL, a common set of standards on how to work towards IL and the same set of available e-learning resources, each library has come up with a different set of learning support mechanisms for its particular institute. So why do people trained in the librarian profession produce such a wide range of different instructional products and material? This may be a result of all academic libraries being unique and existing to serve the particular individual needs of their local scholarly community. Different institutions have different subject-based priorities, and subject or liaison librarians whose skills are largely acquired through experience have been the main drivers in IL and take their different, subject-specific, experiences to IL development. The use of different e-learning resources may also be a result of the different ICT skills amongst library staff. Any library will have a wide variety of skills within its staff members and ICT skills are only one of the many skills sets needed for a library to function. Another factor is that the age range of library staff is such that some staff have witnessed many developments and false dawns in learning technologies; 
The development of learning technologies over the past 20 years can be roughly divided into three overlapping phases: the multimedia phase, the internet phase and the virtual learning environment (VLE) phase, which includes the development of managed learning environments (MLEs). (Liber cited in Melling, 2006, p. 31)

Some librarians have experienced the emergence of all of these learning technologies and the grand claims that attended their inception. Experience has made us innately cautious in approaching certain of the newer technologies. Some of our more experienced and valued librarians are also not necessarily content to embrace a new social networking 'folksonomy' or accept the Google page ranking algorithm as the best method of searching for information on the web - and rightly so.

A lot of the development of IL within libraries and the technological mechanisms used to deliver IL instruction could have been characterised as champion-based - in the sense that a few converts within any given institution drove IL and were at the forefront of investigating and adopting the suitable technologies for its delivery. Across the academic libraries now, one gets the distinct impression that each is keeping a watching brief on other libraries, both here and abroad, and approximating other IL curricula into their own library IL programmes, and that something similar is occurring with the technologies being adopted. The danger in this localism approach is that some smaller libraries with fewer staff will get left behind. Although the new generation elearning technologies, with their ease of use and development, provide great opportunities for libraries to promote their IL strategies, they also pose a challenge for resource stretched librarians who have to master these technologies before they can utilise them as platforms for IL delivery. There is also a fear that without any firm pedagogical reason for using certain technologies, some of the larger libraries may end up using the latest web offering because it is viewed as an advance.

It may be surprising to some that libraries in the academic sector in Ireland have no common strategy on information literacy and therefore no collective strategy on the best practice on using future technologies in the delivery of IL modules. This shouldn't be surprising though when we consider that the IL project is such a large topic for such a diverse profession that a singular, collective approach would seem to be almost impossible to achieve. What is beginning to emerge is that some libraries and partnership of libraries have sought funding to produce IL modules and online courses that would have some common IL approach for at least some aspect of the subjects covered by the institutions. Another method of advancing a common approach is to look at the IL digital content as reusable learning objects and allow libraries to share their e-learning content with each other. Recently the Higher Education Authority in Ireland funded the National Digital Learning Repository (NDLR) to provide a repository of reusable learning objects, and IL (or Information Skills) has now its own community of practice within the NDLR. The IL reusable learning objects do not constitute a full prescriptive curriculum, however, and can be viewed as a list of the ingredients towards making an IL curriculum. The search for a common generic IL curriculum and method of delivery has largely remained elusive and this goal could become the white whale to the Ahabs of librarianship.

The difference of application of e-learning technologies isn't just a phenomenon within libraries, as most third-level institutions and indeed most departments within these institutions operate almost autonomously from other institutes and departments. What is produced in the e-learning environment (because it is usually viewed as a non-core element of teaching and learning within academic institutions) has the hallmarks of departmental innovation trophies that show the department in a better light as it was produced unsolicited by the developers. However innovation, whatever the motivation, cannot be knocked. Innovation leads to advancement, 
however incremental this may be. This laissez-faire attitude to e-learning may be changing though, as department by department and institution by institution each attempt to devise their own guidelines and policies on e-learning and this groundswell of e-learning content will make the adoption of a common policy and set of objectives an imperative. The situation nationally remains that we have no comparable body to the UK's Joint Information Systems Committee (JISC) that exists to coordinate 'activities support education and research by promoting innovation in new technologies and by the central support of ICT' (JISC, 2009)

Another very real consideration is that the various Irish academic institutions have differing local governance structures within their institutes. Different stakeholders are charged with responsibility and ownership of the e-learning content and delivery. Most institutes have a legacy of rigid departmental structures that can act as a deterrent to development of e-learning because the skills that are needed to develop these resources are spread across so many different departments. The sound pedagogy may be found in the academic departments, the ability to find and access the information with the library and the technical skills needed to develop and integrate the technology into the institution's infrastructure lies within the computer service departments. If not handled correctly the tensions that can exist between different departments with separate missions can be a very great impediment to developing a shared e-learning strategy. The level of collaboration to bring the different skill sets together may not be institutionalised and policy driven at the highest level. Often it comes down to how different departments within the institute interact with each other or even to how particular academics view the role of libraries and support departments, or indeed how these support departments actually view their own role. With all this in mind I will now describe our own experience with creating an e-learning environment for IL.

\section{A Case Study of Information Literacy and E-learning Development}

The Dundalk Institute of Technology library's IL programme began with a growing need to organise and formalise a coherent structure for library instruction because of the increasing demand for instruction on the ever growing digital resources of the library. In 2005 we adopted the term Information Literacy more as a library ensign to march under rather than for any great love of the rather clumsy term. As we were coming quite late to the formulation and practice of IL we had many examples of structured IL implementations in other academic libraries to call on. Also the literature and research on IL was quite mature, particularly from the USA, and we, like a lot of other smaller institutions, assimilated ready-made definitions and standards that we felt most suited our needs. Looking back at the documents we produced about IL at this time it is clear that the adoption of standards and structuring the actual IL output was one of our main concerns.

The American Library Association definition of Information Literacy quoted above was adopted by us to serve as our IL definition and the SCONUL (Society of College and University Libraries) seven pillars model of information literacy was used to define what exactly we meant by IL in terms of quantifiable skills. The seven headline skills are identified as

1. The ability to recognise a need for information

2. The ability to distinguish ways in which the information 'gap' may be addressed

3. The ability to construct strategies for locating information

4. The ability to locate and access information

5. The ability to compare and evaluate information obtained from different sources

6. The ability to organise, apply and communicate information to others in ways appropriate 
7. The ability to synthesise and build upon existing information, contributing to the creation of new knowledge. (SCONUL, 2003)

These became the basis for a practical working model. Learning from other libraries' IL syllabus we decided to divide the IL competency levels into three 'streams' that ranged from beginners in Stream One through to more advanced classes for postgraduate students in Stream Three. Within these three streams we constructed a series of modules with their own learning outcomes and lesson plans. These modules were primarily tool descriptors or instructional modules on the different resources the library could offer. At the time we decided to put our IL presentations on PowerPoint slides to deliver to students. There was a lot of good instructional material that we had already produced for instructional leaflets, web content, etc., and it was quite natural to adapt this to slide format. We did not examine any other alternatives to slide presentation at this stage, because frankly when producing a full IL suite of classes in a few summer months, the merits or otherwise of particular technological methods of delivery seemed rather low down on the list of priorities.

The emphasis was on collecting our existing instructional material, creating new material to fill any gaps and structuring it around the IL philosophy. We may have used IL arguments to convince ourselves and academics of the need for IL but I' $m$ not sure we had the material to meet all the standards set by IL. We were content to rely on creating the instructional content as a signifier of our intention to honour the lofty ambitions of IL. Not being trained instructors we perhaps overlooked what the students' experience of the IL instruction would be, and the final two pillars dealing with communicating and synthesising information were maybe a bit beyond our expertise at that time. We had no real conception of how to create interactive or challenging learning processes. How students actually learned was a sort of magical process that we had only a basic knowledge about.

The classes were devised as a list of hour-long instructions on searching the library catalogue, using the different databases we subscribed to, searching e-journals and websites, and using referencing and citation methods. Other more theoretic modules were devised on accessing the quality of information and devising search strategies. With these modules we were in many respects still within the traditional librarian comfort zone of familiarity. Library working groups were assigned to develop each module. There were intensive efforts made at compiling what we as an academic library collectively knew. The fact that staff were also upgrading their own skills was an unforeseen, but welcome, consequence of this process. Indeed the exercise served to enlighten some of us on the full capabilities of the databases, catalogue features, referencing procedures, etc. The IL development process became one of those all-inclusive efforts that served to make us re-evaluate most of what we were doing as an organisation.

An Information Desk was added as a visible sign of what could be characterised as our transition from information storage and provision to also being focused on user support and training. The IL modules were launched, amid much fanfare, upon the wider academic community. The modules were to be offered to lecturers in the new academic year as a service for academic staff to book for their classes. Lecturer buy-in was left purely to their own discretion. In the launch release statement at the time was the exhortation: "Although we advise that the streaming system is followed as it brings new users progressively to information fluency we are flexible enough to allow academics to tailor their own information skills needs, by choosing the modules they wish their classes to take.'

So the modules were generic in origin and not prescriptive in any sense. Not having the temerity at this early stage to insist on students moving through our programme towards becoming 
information literate, and mindful also of the restrictions of time that academic staff had for delivering their own courses, we allowed this à la carte approach for academic staff to select what they felt was most relevant for their students. We understood IL as a process of students moving towards a set of competencies, however, what we were offering was in fact a list of individual instructional sessions on library resources that could be chosen in any fashion by lecturers.

There was also the thorny issue of librarians moving into what was seen as traditional teaching roles, and this was an obstacle for some librarians and academics. Were we now offering a course of IL and should this not be accredited or placed on a more formal recognition within the institute? This issue was somewhat diluted by the generic and optional element to our modules. There was a strong sense of IL being a library 'gift' for our users which sits happily with much of the ethos of librarianship. It was described almost apologetically as a natural extension of our previous working habits of user instruction. But the sheer amount of extra classes we were doing and the concept of IL that we were now espousing made the idea of it being just another development seem quite hollow. In many respects we weren't giving the importance of IL its due respect. Nevertheless even with some design faults, misconceptions and political naivety, we at least had a start made from which to build.

The technology employed for the classes was slideshow presentation format stored on memory discs and delivered within a standard classroom environment, accompanied by paper handouts of the resources we were instructing. As we had no dedicated learning space designed within the library, a conference room facility was adapted for IL delivery, with all the attendant problems for network connectivity, and lack of hands-on PCs for students to do any searching themselves. We also systematically collected the opinions of students about what we were trying to achieve as a means to inform improvements of our content and processes. Storage and harvesting of this content was becoming an issue and quite elaborate spreadsheets with dates and numbers of students were devised. A lot of the initial feedback was quite positive, both from the students and the teaching staff, which gave us encouragement in the initial tentative stages. Our early phase was deemed a general success. We had over 2,300 students completing at least one of these modules within the first couple of months. Rarely had the library been in such demand and the increased use of our services and facilities was seen as a vindication of all the hard work the staff put in. But as the bedding-in process progressed it was becoming clear that we had a lot to learn about our new role.

\section{Issues Encountered}

Notwithstanding the first flush of success, a number of issues were becoming apparent. The first and most obvious one was that the sheer number of sessions booked placed a great deal of pressure on library resources, both in terms of personnel and facilities. We hadn't sought new staff or resources for this extended instructional function. This wasn't an oversight on our part but more an acknowledgement of the reality that no further resources would be forthcoming, and was also indicative of the 'gift' nature of the library's endeavour. Another issue highlighted was that because of the elective nature of many of the institute's courses, different lecturers had inadvertently double-booked some students into the same class. Clearly our booking system needed some modification. We were on a steep learning curve adjusting practices as we went along.

The academic staffs were initially enthused by the idea that we in the library would take students through the information resources that were available to them. The academics were engaging with the IL project as a mix-and-match list of resources to be booked rather than understanding the theories of the IL programme that was designed as a graduated process of training students on 
how to learn. This was, in fact, how the modules were structured and offered to lecturers and perhaps our timidity was undermining the important issue of guiding students on an IL project. From a library staff point of view, there was no distinction made between library staff that were subject liaisons and had better experience to present instruction on information resources and those who were not as well equipped to speak confidently about resource discovery. Having a small number of staff we may have created the mistake of placing some staff in stressful situations. The motivation for the staff in taking this extra workload on-board was not uniform. Some did it more as a duty than with conviction. These teething problems would create an unnecessary hostility towards IL in the future. Although we understood that the workload would be front-loaded, I don't think anyone was quite prepared for the disruption to their normal working day in the initial phases. Printing off attendance sheets, feedback forms, guides for particular classes and preparing for the class became a time-consuming part of our working day.

The lack of suitable technology was becoming an issue too. As the college didn't have a content management system, we resorted to storing all our new IL content on the shared drive of the institute server, which had its limitation because of access rights, etc. Having the class content available to students and staff became an issue also. Putting slideshows on the web without explanatory notes leaves a lot to be desired from an instructional point of view. What was becoming very evident was that the range of technologies and the facilities that had been adequate for previous library functions were beginning to creak under the stresses of being used for purposes for which they weren't initially designed. Indeed, it's a testament to the adaptability and patience of the librarians that the introduction of IL went so well. To continue with the broad base of classes we would have to examine new technologies.

Some of the feedback from students was less favourable, and from some of the bored expressions of students who had to sit through 45 minutes of screenshots of our library catalogue being explained to them and from some of the written feedback expressing annoyance at the method of our delivery, we became aware of the need for modification. The experience of sitting in a crowded library room improvised to seat 30 students looking at a projector attached to a laptop was perhaps more of a learning experience for the librarians than for the actual students.

\section{A Work in Progress}

The librarian/tutors began to ask: 'Could we be doing this any better?' Our experiences with classes had the effect of making some librarians think like teachers and learning technologists. The involvement of librarians in the process of IL delivery compelled us to search for new technologies and in particular the possibilities of using available e-learning technologies. What had become apparent also was that we needed to take a fuller, more holistic approach to IL looking at the interdependence of its parts. So in tandem with our prescribed IL instruction, we were beginning to look at the possibility of using newer e-learning resources in a 'blended learning' approach. As the IL project progressed, the discipline of IL began to infuse more of our services with the ethos of providing support and training to our users. The users' needs and our own efforts to bridge the gap in their ability to access information was almost imperceptibly brought centre-stage for us. Our concentration was focused on what we were offering students not only by way of instruction in the face-to-face sessions but also of what library instruction the students could get on the library's web pages and other available platforms. The determination was made that students should be able to access IL instruction from our online resources. We also needed to have the information available to them online, 24 hours a day and seven days a week. We were beginning to ask how and when students needed our services, and the web resources provided a cost effective method of providing these services. The public face of the library became important to portray a more user-friendly and user-focused library service. Posters, 
promotions, library events, and our online content all were judged in relation to how we could improve our dialogue and the instruction content for our users.

Perhaps the interaction between staff and students through the IL sessions encouraged us to look deeper at the issue of communicating to all our users. As we looked at how students were communicating and interacting with each other and correlatively how they were learning, we saw that the web was facilitating an immediacy of communication and simple connectivity solutions for students that could be adapted to our instructional output. These 'social software' solutions required little training on behalf of the users and were, to a large extent, free to use. Both of these factors were real positives for us.

One such example is a blog or weblog. The library developed its own blog around this time, primarily as an online notice board for library news and events. We felt that there was need to circumvent the cumbersome process of placing notification of library-related activities on the web pages hosted on our institutional web server. The immediacy of our blog entries and the feedback potential from students, with the ability of users to leave comments on the interactive and mediated comments board were viewed as important features in our drive for improved communication with students. There had been asynchronous solutions in our communication methods before, like simple email or an 'Ask a Librarian' facility, but these Web 2.0 technologies seemed more in tune with what present-day students were using. Web-based solutions proved inexpensive and were under our total control in the sense that we could easily learn to design and use the interfaces. A shift away from the rigidity of solutions like static web pages was a consequence of our efforts to connect with the users. IL had become the catalyst for change making us look to virtual technologies to support and train our users.

In keeping with the idea of directly interacting with our user to supply information assistance, we recently set up a web chat service, MSN Messenger, that we hope will be a synchronous virtual equivalent to our information desk and an adjunct function of the work done by staff at the information desk. The idea is that students can chat to librarians about queries they may have and receive live feedback to those queries. This service is only in its infancy with us, but its potential value has been verified in other academic libraries that use it. As with a lot of these new technologies, it is relatively easy to set up but requires some thought on the policies and procedures needed to use it, for instance, what sort of information we should respond with, how to deal with nuisance correspondence, how we log communications, etc.

Another simple but effective web-based technology is 'social bookmarking' software that can be used by subject librarians to disseminate their qualified recommendations of websites for specific subject areas. Social bookmarking allows you to create a list of links in one of the social bookmarking sites such as del.icio.us, Connotea, Citulike, etc. These can then simply be hosted as the link on your subject-specific webpage. The bookmarking sites have the advantage of being able to organise and tag sites into groups, so librarians can make searching the websites simpler for their students. Social bookmarking is also a good way for subject librarians to keep an eye on other good subject guides on library sites and keep up-to-date on what's new within the particular 'tags' they are interested in.

By including subject-relevant RSS (Really Simple Syndication) feeds into your web pages, blog or social networking site you can automatically keep your pages dynamic and fresh for users. In many ways these so-called Web 2.0 technologies are helping librarians to bridge the gap towards a semantic web that assists in the interaction between how humans express their information needs and what is understandable by computers. With Web 2.0 technologies like blogs, social bookmarking, and wikis the emphasis is on student interaction. Students should be able to add 
content, comments, or look for assistance as they deem necessary. The versatility of these software solutions encourages librarians to experiment and modify the uses of them for their own purposes. Most importantly for librarians, we do not have to undergo software training to be able to develop them. Another software tool that we now use to augment our online content is Camtasia software. Using this software we were able to produce a series of short instructional videos that can be broadcast over the Internet. We can record demonstration searches using screen capture and audio instruction and even insert flash animation to enliven the content. The files can be produced to allow students to download them as podcast or view them as embedded streaming media files within any browser. We use these primarily as a means of having instruction for students available on the web at any time. These were developed as a direct response to the inadequacies of uploaded traditional slideshows. Another driving motivation for developing webcasts was the idea that students were learning differently and that downloadable instructional webcasts would give them an option to find out about library resources whenever and wherever they chose.

An interesting development in the webcast project was the collaboration with the International Office to translate and dictate a webcast for our foreign students who spoke Cantonese. This came about because of the problem of giving library tours and basic instruction to new Chinese students, with the need for a translator being present. The idea was simply to script a webcast with all the basic information needed for these foreign language students and this would be available for them on the web to view as and when they wished to do so. The script was given to a translator from the International Office to translate and a recording was made of it and synced up to suitable screen captures and flash animation. The whole lot was then compiled and produced as a five to six minute webcast that was be put on the web for download.

The webcast project required a more labour-intensive approach and required a team of developers who had to quickly come to terms with many new and interesting skills such as script writing and voice delivery. Having a team member who knew how to develop and add Flash animation to the webcasts greatly enhanced the look and feel of these online instructional videos. The Camtasia software also allows you to create interactive instruction with navigation aides and pop quizzes at the end of instructional sections. Some libraries have developed very clever and innovative ways to demo their resources with these interactive audio tutorials. We are hoping to develop our webcasts along similar lines in the near future. It is also important to note that, as with much webbased content we do not have to re-invent the wheel and a lot of good information is freely available to access on the web, developed by database vendors, web search engines, etc. A trawl through the web and You Tube may produce some valuable material or at least a good indication of where you should start.

With our face-to-face IL sessions we were finding that some library staff began to become more comfortable in the classroom environment and were starting to improvise and experiment with the traditional class process. Some of our librarian/tutors were beginning to intuitively interact with their classes and were going off-script from the slideshow presentations. Librarian/tutors felt it more natural to ask the students questions and to do more 'live' searches on databases and web searches of student queries in order to engage the classes in the process of information retrieval. So network points for access to the web became a hardware requirement for the IL classes. Other basic interactive web-based tools were discovered to engage students in answering questions in class. Simple questions were put to the class looking for answers, which would then be answered on the browser screen via a java applet. The simple act of asking students for a response was engaging students' cognitive faculties and hopefully awakening their intellectual curiosity. This was an important development as it meant that we as instructors were now becoming more interested in eliciting responses from our students and more concerned that the instruction was 
being delivered in an effective manner. We were beginning to feel the pride of teaching well. We did look at how other libraries were dealing with conducting classes and options were examined such as the 'clicker' technique, but this was dismissed as being too expensive and time consuming to set up.

Another e-learning solution is an online learning tutorial that allows students to go through the tutorial at their own pace. Once again there is no need to develop your own software for this as ready-made packages exist for libraries to adapt and customise for their own needs. Some libraries went to great lengths to develop their own online tutorials but many different academic libraries have adapted their own version of these freely available tutorials. We went down the adopt-and-adapt route in order to have an online tutorial ready to roll out for the beginning of the academic year.

The range of resources and different links to completely separate sites managing your library content and services may begin to resemble a patchwork quilt and it is imperative that a wellstructured library website is developed to capture all these different resources into a coherent easily navigable structure for users. As with so much else a proactive computer services department or cooperative institution web developer is a real bonus in managing the first portal that users go to. Our website was completely overhauled recently and the results are very satisfactory. The pages on library web interface are some of the most widely used pages on the whole institution site.

One question you need to ask yourself when developing any e-learning product is how effective it will it be and whether it warrants the time developing it for its perceived reward? There is a school of thought that suggests that purely online unmediated courses can leave the students cold and that the level of attainment of learning cannot go above proficiency with pure web-based instruction. Dreyfus (2009, p. 128) argues that 'acquiring skills requires involvement and risk', but that using e-learning technologies in conjunction with face-to-face teaching 'helps students stay informed as to what is going on in the course.' So we should temper our enthusiasm for stand-alone online courses, and always encourage users to engage with our IL sessions where possible.

At the same time as IL sessions were becoming integral to our working day, other developments elsewhere within the institute were taking shape. An institutional virtual learning environment was developed and some of our academics had begun using it. This was an Open Source product, Moodle, and was developed locally by interested champions. Moodle is a software e-learning platform, designed to help educators create online courses with opportunities for rich interaction with the students. Many of the academics have now progressed from using it as a type of document management system where they stored class materials to actually utilising its more interactive capabilities. It would be fair to say that at its inception the library hadn't fully appreciated the importance that this e-learning tool would have for our IL delivery. Initially the library only expressed an interest in having 'a presence' on the new VLE, to advertise our service on it and perhaps to investigate the possibilities of hosting our presentations and documents on it, as a sort of makeshift content management system. We did have some training in using the VLE but at that time we saw it primarily as a vehicle for the academics.

\section{Embedded IL}

Recently one of the more interesting developments in IL instruction occurred when a lecturer asked for a series of IL classes as part of the Research and Writing course for a first-year Business Studies group. The lecturer had decided to opt for the whole suite of Stream One IL instruction modules that were available. With this level of involvement the subject librarian was 
usually assigned the role of instructor. As I was the business studies liaison, I decided to ask the lecturer to arrange a lab in the Business Studies department for these classes. Learning from past experience, I wanted to incorporate some element of student activity within the class. The simple premise at the time was to give the IL presentations, and then give a sheet of questions to the students to answer on what had been presented using the PCs in the labs. The lecturer was happy to oblige with arranging lab bookings and I set about devising relevant questions for these classes. Given the level of involvement of students in the IL classes, the lecturer decided that the students should be awarded marks as part of their continuous assessment for the Research and Writing course. This accreditation was an important element in 'embedding' IL modules into a first-year course. This was an opportunity to test the theory of best practice within IL of embedding IL into actual courses.

In its first year the course relied heavily on the presentations and printed material for instruction. The structure of the course was divided into the IL learning modules that were already on offer, such as searching the library catalogue, searching databases, searching the web, referencing and evaluation of information resources. The time in the class would be divided into tutor presentation time and time spent by the students using what they had learned to find information on the PCs. Different sets of questions were devised for the students to answer at the end of each presentation that related to the students demonstrating that they could access and find material on the particular resources that had been taught to them. The examination at the end of the course was answered on paper but required the students to use computers.

We began to really see the importance of students applying what was being taught in a lab situation. Having students apply their knowledge within the class was easier and more effective than talking at them for an hour. The exams were conducted and all students passed without exception, which wasn't really a surprise as the content of the examined material was well flagged in advance and not on the difficult side. There was a pretty steep learning curve for these sessions as you had to organise the classes like a teacher and make sure the technological hardware was working properly before-hand. It was also surprising to me how involved one became as a tutor and anxious that the students learn as much as possible when there were actual marks awarded for the course.

When it came to reviewing the project with the lecturer at the end of the first term, the lecturer expressed satisfaction with the experience and said that the students benefited greatly from the IL course. Unfortunately though, she revealed that she had witnessed no discernible improvement in the bibliographies and, evidently, the depth of research from these students in their other firstyear assignments. No 'inductive transfer' or 'learning transfer' was taking place between what was being taught in the IL sessions and their other research. This was quite a surprising observation as a good deal of emphasis of the instruction was focused on broadening their resource discovery skills. The conclusion we made at the time was that students had the ability to compartmentalise the different strands of their first-year courses. This was after all what they were used to doing in secondary level education. They viewed the library part of their course in isolation from the rest of their studies. It was just another module to be passed and they hadn't made the connection that the library IL skills was a universal set of skills that should be transferred to the other aspects of their courses. This compartmentalising of IL into just another class to be passed was disappointing and defeated one of the main tenets of IL - that it gives students transferable skills they can utilise in other courses. The students demonstrated reluctance to use more in-depth search strategies which meant that they were falling back on their prior knowledge and had not learned how to learn differently. They were falling short of the goal we set ourselves of moving them towards being independent learners. It was becoming clear that the structure of the IL sessions and our methodology were at fault. A solution we thought would be to 
take some of the students' other course assignments and incorporate the information needs of these assignments into the IL part of the course. We needed to make the study skills and advanced research methodology a seamless part of what they did for third-level learning.

The following year we ran the same classes again, this time incorporating the assignments into the modules. If we were doing a class on database discovery I would have prior knowledge of student assignments and incorporate the assignment keyword searches into the class and require that the students use the PCs to find information on their assignments. Then we would spend some time evaluating the results. This was quite successful and the students were glad to have a library facilitator there to help them get the information for upcoming assignments. Again the students did well with the formal examinations but this time from both the academics involved and from a librarian and an IL perspective it was felt that students took more away from the sessions than the previous year. By pure coincidence I had happened upon the teaching theory and methodology and was beginning to see the benefits of using a system that involved students more in their own learning process. Elements of problem-based learning and constructivist psychological theory of knowledge and teaching methods were creeping into these IL instruction sessions. In particular the idea that students should work in collaborative groups within a lab situation to discover for themselves what information resources were of value for their course work, and that these labs could be facilitated by information professionals such as librarians represents a new and more effective way to deliver IL

\section{Using the Virtual Learning Environment}

One of the key developments from these embedded sessions was the request by some of the students to have the material that was delivered in class accessible in electronic format. This made us examine how we could use the VLE to put presentations and other material onto it for students to access. In the process of doing this it became clear that using the VLE simply as a content management system was not using its full potential and we were simply placing all our existing documents into the VLE, without much care for adapting the content to the new platform; 'Shovelware' is a disparaging term to describe this practice. There were resources and activities that could assist in a more involved method of teaching the students that both the lecturers and librarians wished for. Not only could you lay out the structure of your weekly courses and upload the resources you wanted students to access from the class, but you could develop and add web pages and list web links suitable for each week's course. There were also facilities to add quizzes for each class, forums to allow students to post their queries and informational needs. Chat rooms, wikis and a facility to create blogs were also features that provided interesting avenues of interaction for instructor and student and from student to student. We could also interact with the students using the survey facility of the VLE. Another useful function within the VLE allows students to upload word documents, for instance, which means that tutors can set assignments for students and students can then upload these assignments for correction when they are finished. Also there was a facility to manage online quizzes or assignments that could be graded by the administrator and made available immediately to students. For the administrators and teachers there were question banks that were effectively repositories of questions that other librarians could use. We needed to quickly learn about SCORM, (Sharable Content Object Reference Model), standards compliant questions format that allowed us to create interactive questions for the VLE.

The potential for augmenting our IL classes in a blended manner using the VLE is so great, that a whole re-think of our content and what we can do in the classroom situation has opened up before us. We can truly incorporate collaborative content into the classroom environment using the VLE. The VLE is a clear instance where the technology has facilitated the development and future direction of what we intend to offer in IL over the coming years. In the future content will be 
structured into five different classes. The class time will be divided into the PAR model of teaching: Present, Apply and Review. There will be a presentation for 15 minutes, followed by structured application by the students of what they have learned using the lab PCs for a further half hour, followed by a class discussion and reviewing process of the quality of the information that they harvested at the end of the class. There is an online forum where students are asked to post their questions either on their first-year assignments or on broader queries about information retrieval. These will be answered in the next class or as soon as possible. This approach has some aspects of computer-supported collaborative learning (CSCL) in the sense that the VLE provides the virtual scaffold for students to communicate and share the solutions to their information needs of a shared assignment. The lecturer also expressed an appreciation with the forum because the lecturer has been assigned the co-teaching role within the VLE module and can see what the class is discussing and what questions they are asking, which gives an insight into how they are progressing and whether they are asking the right questions.

The classes are now structured so that the IL sessions provide targeted intervention for first-year students at the beginning of their studies and just after they have been given their first assignments. This is in the hope that students feel that these sessions are actually addressing their real curricular needs. Contextualisation of what they are doing in the IL sessions, and relating their work to other parts of their curriculum, makes the work in the sessions more urgent and relevant for the students (and useful to the lecturer!). The fact that they are developing good IL practices about information seeking, retrieval and evaluation and that they are learning how to learn in a real environment is the IL bonus for the library.

\section{Future Developments}

One of the most interesting developments has been the collaboration between academic and librarian to achieve real progress in the provision of IL to embedded students, and how the VLE supplied some of the pressing issues we had with IL delivery. The constructivist psychological theory and the problem-based learning models that some academics are themselves adopting and developing, I believe, complement many of the standards we set ourselves in IL and re-enforce what has been our experience of IL delivery. The roles of subject or liaison librarians are vital to fostering the collaborative partnership in this new dynamic between academics and library. It also requires trust to be built up between academics and librarians, to share their curriculum and proposed learning outcomes and a willingness to modify their classes to incorporate the IL principles. Meetings between lecturer and librarian must be timely and frank for a common structure and mutual trust to be developed.

There are two basic platforms for e-learning for librarians to consider in their delivery of IL. Firstly there is the stand-alone, web-based and unmediated platform where instructional content can be hosted. Websites with subject-based portals or resource guides, web-based tutorials, webcasts, audio recordings, virtual tours, synchronous and asynchronous methods of relaying information to students. These are some of the technologies employed through this platform. Secondly, there is the blended learning platform with a tutor/facilitator teaching an IL course and utilising a variety of technologies to enhance the classroom experience. These classes are particularly effective in instructing students how to use information resource locators like ejournal databases, or how to search the web with various search engines, or how to reference correctly. A further development of these classes is the embedded IL instruction that requires more design cooperation between librarian and academic. These embedded IL courses created in collaboration with academics and tailored to be subject-specific are delivered in an interactive and meaningful way to students that will augment their chosen course of study. Having IL and the course syllabus unite in the common purpose of creating independently minded and information- 
aware students seems to be a very promising development for academic librarians, academics and students alike. This is as far as we have come on our IL and e-learning journey, so far.

Looking to the future, the idea of student group work within the classroom or lab is an avenue that we intend to explore. Giving students problems to find information related to their course work and the librarian acting as a facilitator and guide within this learning environment seems like a very constructive approach, but one that needs to be developed in collaboration with lecturers: 'Instructors and librarians contribute to the session by collaborating on objectives and learning goals, creating research questions, recommending lists of resources, and questioning' (Snavely, 2004, p. 529).

As always we are looking to improve IL delivery for our users, and it may be that what is needed now is a systemic approach to creating a set of classes that would be obligatory as part of a firstyear orientation course. This would need to be part of an institution-wide effort to develop instructional models that would seek to develop students as independent thinkers. Each school or faculty within the institution would need to be involved with the relevant support services to bring this about. The institutional VLE is an ideal e-learning environment to host such a suite of subject-based IL modules. The librarian's input would be needed in developing learning outcomes and instructional content to help students locate and evaluate resources. These agreed learning outcomes and instructions could be incorporated into problem-based learning classes that were based on the actual student's chosen course of study and something that the academics could perhaps instruct themselves upon. (As long as IL is devised and delivered correctly, there is no reason why librarians should be the sole instructors.) Such an approach may help address the phenomenon of web savvy-students 'getting by' with poor research and IL skills. It would also address some of the issues of librarians being over-stretched with their instructional duties and serve to firmly embed IL concepts into the teaching discourse. A systematic acceptance of IL would take a lot of management commitment and organisational coalescing that is beyond the remit of the library to affect. However, the overlap in philosophy and goals between IL and problem-based learning may allow librarians, working in collaboration with problem-based learning inclined lecturers, to further IL instruction. Of course there would be departmental considerations and timetabling issues to address, but just because it is difficult to achieve should not make it impossible, especially if we who work within the academic world are serious about creating an information society.

\section{CONCLUSION}

At present the variety and scope of the e-learning technologies available to librarians offer us diverse ways to present IL to the community we serve. I believe we must tailor our IL content for that community in a way that best suits our resources. The convergence of increasing volume of information, a need for librarians to instruct users how to access this information, new practices in the broader teaching world and emerging e-learning technologies has opened up a very real possibility of repositioning the academic library as central to the education process. It is tempting to say that technology and the discovery of e-learning tools revolutionised our IL output and therefore the way we as librarians work. But I think that this would be an over-simplification of the whole process of IL introduction that I have detailed. IL re-orientated our attention to a more student-focused agenda and informed many other practices we do within the library. The convergence of information literacy and e-learning technology, aligned with new teaching practices certainly makes it possible to create this new dynamic. Each of these forces, though, should not be taken in isolation, as it would distort our main aim to instruct library users in the skills needed to navigate the complex information world.

\section{REFERENCES}


American Library Association. (1989). Presidential Committee on Information Literacy: Final Report. Retrieved March 23, 2009, from

http://www.ala.org/ala/mgrps/divs/acrl/publications/whitepapers/presidential.cfm

Dreyfus, H.L. (2009). On the Internet ( $2^{\text {nd }}$ ed.). New York: Routledge.

Melling, M.E. (Ed.) (2006). Supporting e-learning: A guide for library and information managers. London: Facet Publishing.

Joint Information Systems Committee. (2009). About us. Retrieved March 24, 2009, from http://www.jisc.ac.uk/aboutus.aspx

Society of College, National and University Libraries. (2003). Information skills in higher education: A SCONUL position paper. Retrieved April 2, 2009, from http://www.sconul.ac.uk/groups/information_literacy/papers/Seven_pillars.html

Snavely, L. (2004). Making problem-based learning work: Institutional challenges. PortalLibraries and the Academy, 4(4), 521-531.

\section{ADDITIONAL READING}

Blake, L. (2009). On Campus or out of town: How publishing online tutorials can help your patrons. Computers in Libraries, 29(4), 11-13.

Blummer, B. (2007). Utilizing webquests for information literacy instruction in distance education. College \& Undergraduate Libraries, 14(3), 45-62.

Blummer, B. (2008). Applying Perkins's facets of a learning environment for information literacy instruction. Community \& Junior College Libraries, 14(3), 179-189.

Buchanan, L.E., Luck, D.L., \& Jones, T.C. (2002). Integrating information literacy into the virtual university: A course model. Library Trends, 51(2), 144.

Burton, V.T., \& Chadwick, S.A. (2000). Investigating the practices of student researchers: Patterns of use and criteria for use of Internet and library sources. Computers and Composition, 17(3), 309-328.

Callison, D. (2009). Instructional trends from AASL journals: 1972-2007. Part 3: From accessmeasured to evaluation-measured. School Library Media Activities Monthly, 25(10), 2528.

Corcos, E., \& Monty, V. (2008). Interactivity in library presentations using a personal response system. EDUCAUSE Quarterly, 31(2), 53-60.

Dreyfus, H.L. (2002). Anonymity versus commitment: The dangers of education on the Internet. Educational Philosophy \& Theory, 34(4), 369-378.

Fosmire, M., \& Macklin, A. (2002). Riding the active learning wave: Problem-based learning as a catalyst for creating faculty-librarian instructional partnerships. Issues in Science \& Technology Librarianship. Retrieved October 26, 2009, from http://www.istl.org/02spring/article2.html

Grafstein, A. (2007). Information literacy and technology: An examination of some issues. Portal: Libraries \& the Academy, 7(1), 51-64.

Griffin, D.K., Mitchell, D., \& Thompson, S.J. (2009). Podcasting by synchronising PowerPoint and voice: What are the pedagogical benefits? Computers \& Education, 53(2), 532-539.

Johnson, D., \& Eisenberg, M. (1996). Computer literacy and information literacy: A natural combination. Emergency Librarian, 23(5), 12.

Kenedy, R., \& Monty, V. (2008). Dynamic purposeful learning in information literacy. In M.M. Watts (Ed.), Information Literacy: One Key to Education. New Directions for Teaching and Learning, 114, San Francisco: Jossey-Bass.

Lincoln, M. (2009). Information literacy: An online course for student library assistants. School Library Media Activities Monthly, 25(10), 29-30.

Macklin, A.S. (2001). Integrating information literacy using problem-based learning. Reference Services Review, 29(4), 306-314. 
Orme, W.A. (2008). Information literacy and first-year students. New Directions for Teaching and Learning, 114, 63-70.

Pope, A., \& Walton, G. (2006). Information literacy: Recognising the need. Oxford: Chandos Publishing.

Rogerson-Revell, P. (2007). Directions in e-learning tools and technologies and their relevance to online distance language education. Open Learning, 22(1), 57-74.

Slaouti, D. (2002). The World Wide Web for academic purposes: Old study skills for new? English for Specific Purposes, 21(2), 105-124.

Spence, L. (2004). The usual doesn't work: Why we need problem-based learning. Libraries and the Academy, 4(4), 485-493. Retrieved October 20, 2000, from http://muse.jhu.edu/login?uri=/journals/portal_libraries_and_the_academy/v004/4.4spenc e.html. doi:10.1353/pla.2004.0072.

Stephen, M., Trywell, K., Kgomotso, M., \& Justus, W. (2006). Design and implementation of an online information literacy module: Experience of the Department of Library and Information Studies, University of Botswana. Online Information Review, 30(2), 168187.

Sundin, O. (2008). Negotiations on information-seeking expertise: A study on web-based tutorials for information literacy. Journal of Documentation, 64(1), 24-44. Retrieved from http://www.emeraldinsight.com/Insight/ViewContentServlet?contentType=Article\&Filen ame $=$ Published/EmeraldFullTextArticle/Articles/2780640102.html. doi:10.1108/00220410810844141.

Viggiano, R.G. (2006). When faculty behave like students: Teaching faculty about online library resources. Journal of Library Administration, 45(3/4), 563-563.

Williams, J., \& Chinn, S.J. (2009). Using Web 2.0 to support the active learning experience. Journal of Information Systems Education, 20(2), 165-174. 